\title{
冀西北水源涵养区不同类型人工针叶林 生态功能差异性评估
}

\author{
孙菲菲,张增祥,左丽君, 赵晓丽, 潘天石, 朱自娟, \\ 汪 潚, 刘 芳, 易 玲, 温庆可, 徐进勇, 胡顺光
}

(中国科学院遥感与数字地球研究所, 北京 100101)

\begin{abstract}
摘要：人工造林被认为是增加碳汇、保持水土和提高水质最有效的方法之一, 造林林种的不同 将产生不同的生态效应。通过调研土壤、气象及生态化学计量参数等对 CENTURY 模型进行 本地化, 模拟冀西北水源涵养区主要针叶造林树种 [落叶松 (dahurian larch)、油松 (pinus tabulaeformis)、侧柏 (oriental arborvitae) 和樟子松 (Pinus sylvestris var. mongolical)] 的生态效应, 并 结合文献数据评价模型拟合精度。模型模拟结果显示: 与幼龄林相比, 落叶松、油松、侧柏和 樟子松中龄林的土壤 C、N、P 总储量分别增加了 $3.37 \% 、 3.98 \% 、 2.84 \%$ 和 $1.82 \%$, 土壤含水量增 加了 $151.25 \% 、 73.62 \% 、 41.83 \%$ 和 $94.98 \%$ 。不同林种两个林龄平均蒸发量比较显示, 落叶松 $(338.85 \mathrm{~mm})<$ 油松 $(399.86 \mathrm{~mm})<$ 侧柏 $(400.52 \mathrm{~mm})<$ 樟子松 $(401.82 \mathrm{~mm})$ 。落叶松可以作为水 源涵养区造林的优选树种。樟子松和落叶松具有较强的 N、P 吸收能力, 建议在农业污染的下 游区域推广樟子松和落叶松的种植。
\end{abstract}

关键词: 生态功能;CENTURY 模型; 水源涵养功能;人工针叶林;养分固持

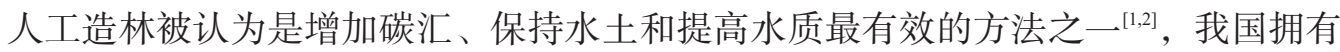
世界上面积最大的人工林。人工植被的营造对土壤养分和水源的涵养既有积极的改善作

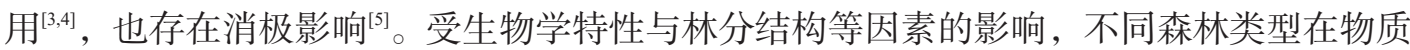
周转、调节以及养分归还等过程存在差异，导致土壤理化性质对不同林种的响应不同 ${ }^{[6,7]}$, 最终表现为森林生态效应的差异。因而, 人工造林对生态系统服务功能的构建不仅与造 林区域的气候与土壤有关 ${ }^{[8]}$ ，也与造林树种、造林密度和经营管理措施的差异有关。以水 源涵养为例, 通常认为阔叶林土壤水源涵养功能优于针叶林 ${ }^{[0]}$ 。但也有学者发现, 针叶纯 林以及针阔混交林 ${ }^{[10,11]}$ 中土壤的持蓄水能力优于阔叶纯林。因此, 针对特定区域, 研究由 林种不同引起的生态服务功能及生态效应差异，对人工造林空间配置和生态建设具有指 导意义。

植物一土壤一大气之间 $\mathrm{C} 、 \mathrm{~N} 、 \mathrm{P}$ 和水分等物质循环过程机理的良好模拟是合理评估 生态系统功能的前提。以 CENTURY 模型为代表的生物地球化学循环模型（Biogeochemical Cycles，BGC）侧重于营养物质交换过程的模拟，同时考虑了植被类型造成的生物物 理参数分异和人为干扰 ${ }^{[12]}$, 是应用最为广泛的模型之一。CENTURY 模型对土壤碳、氮 元素循环的处理过程和模拟方法被许多 BGC 模型所借鉴, 成为 CENTURY 模型的特色 ${ }^{[13]}$ 。

收稿日期：2019-07-04; 修订日期：2020-01-07

基金项目：国家水体污染控制与治理科技重大专项（2017ZX07101001）

作者简介: 孙菲菲 (1984- ), 女, 山东德州人, 博士, 助理研究员, 研究方向为土地利用与生态遥感应用。 E-mail: sunff@aircas.ac.cn

通讯作者: 左丽君 (1983-), 女, 江西上高人, 博士, 副研究员, 研究方向为土地利用可持续化遥感。

E-mail: zuolj@radi.ac.cn 
CENTURY 模型最初用于对草地生态系统 ${ }^{[14]}$ ，现已广泛用于欧洲 ${ }^{[15]}$ 、南北美洲 ${ }^{[16,17]}$ 以及亚 洲的温带、热带地区的森林和农田等生态系统 ${ }^{[18,19]}$ 。CENTURY 模型在我国内蒙古典型草

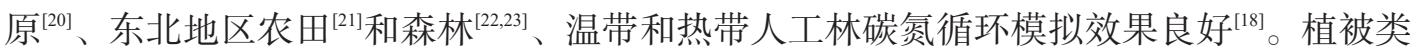
型是 CENTURY 模型最重要的输人量，当植被类型确定后，物质在生态系统各组分之间 的传递过程就仅仅是气候和土壤的函数, 因此, CENTURY 模型对土壤参数和初值设定 要求较高, 属于具有初值依赖性的模型 ${ }^{[13]}$ 。

本文以位于京津冀西北生态功能涵养区的张家口市作为研究区域，模拟并比较主要 人工造林树种的水源和养分涵养功能。受气候和土壤因素影响, 蒸发散和生长需水量相 对较小的针叶林种成为张家口水源涵养造林的重要林种。张家口人工针叶林面积占其人 工乔木造林面积的 53\%，占其水源涵养造林面积的 $80 \%$ 。统计显示，2017 年，张家口市 森林覆盖率为 $38 \%$, 且尚有面积约为 $1800 \mathrm{~km}^{2}$ 的宜林荒山荒地。不同造林林种的生态功 能模拟和效应对张家口市水源涵养功能和生态支撑功能的保持与增强效果如何, 是目前 亟待解决的问题。这一问题的回答不仅对人工林种的合理配置和生态空间格局的优化具 有重要价值, 对保障京津冀生态安全也具有重大意义。研究采用 CENTURY 模型对落叶 松 (Dahurian larch)、油松 (Pinus tabulaeformis)、侧柏(Oriental arborvitae) 和樟子松(Pinus sylvestris var. mongolical) 四种主要人工针叶林种的生态功能进行模拟和适用性评价, 通 过对比四种人工针叶林不同林龄的养分固持、消耗及损失的变化和差异，评价不同人工 造林林种对改善生态环境的意义。

\section{1 研究方法与数据来源}

\section{1 研究区概况}

张家口市面积 3.68 万 $\mathrm{km}^{2}$ ，是京津冀地区的水源地和防风固沙屏障，也是京津冀发 展规划的生态涵养区。张家口市地势西北高、东南低, 海拔范围 320 2841 km, 阴山山 脉横贯中部，将全市划分为坝上、坝下两个自然地理区域。坝上张北高原，属内蒙古高 原南缘, 面积为 1.25 万 $\mathrm{km}^{2}$, 植被主要为温带草原, 坝缘和滨湖地带有少量森林分布, 天然植被主要以小叶锦鸡为主, 人工植被主要有杨、榆及落叶松、樟子松等。南部坝下 地处华北平原和内蒙古高原的过渡带, 面积 2.44 万 $\mathrm{km}^{2}$, 多石质山地和丘陵盆地; 盆地 自然植被较少，主要为灌木草原，坝下中东部植被覆盖度较好，天然植被主要有山杨、 桦木、栓皮栋、山杏等; 人工植被有杨、落叶松、油松等。区域内以水源涵养、防风固 沙、水土保持和防护用材等生态功能为目标的人工林体系复杂多样，但是造林模式相对 单一, 以人工纯林为主。同时, 张家口是全国水资源紧缺地区之一。全市多年平均降水 量 $400 \mathrm{~mm}$ 左右, 年蒸发量高达 1400 1700 $\mathrm{mm}$ 。此外, 张家口土壤类型多样, 有棕壤、 栗钙土、栗褐土、褐土、灌淤土、草甸土、水稻土和风砂土等 8 类。

本文以张家口市 2016 年林业小班数据为林种分布背景数据，在落叶松、油松、樟子 松和侧柏的主要分布区域, 针对相同林种, 选取土壤质地及立地条件相近的幼龄林和中 龄林样点, 进行 CENTURY 模型模拟, 对比不同林龄和林种的生态功能差异。样点空间 分布位置如图 1 所示。

\section{2 模型与方法}

\subsection{1 模型概述}

CENTURY 模型结构包括森林子模型、土壤有机质子模型、作物/草地子模型和水分 


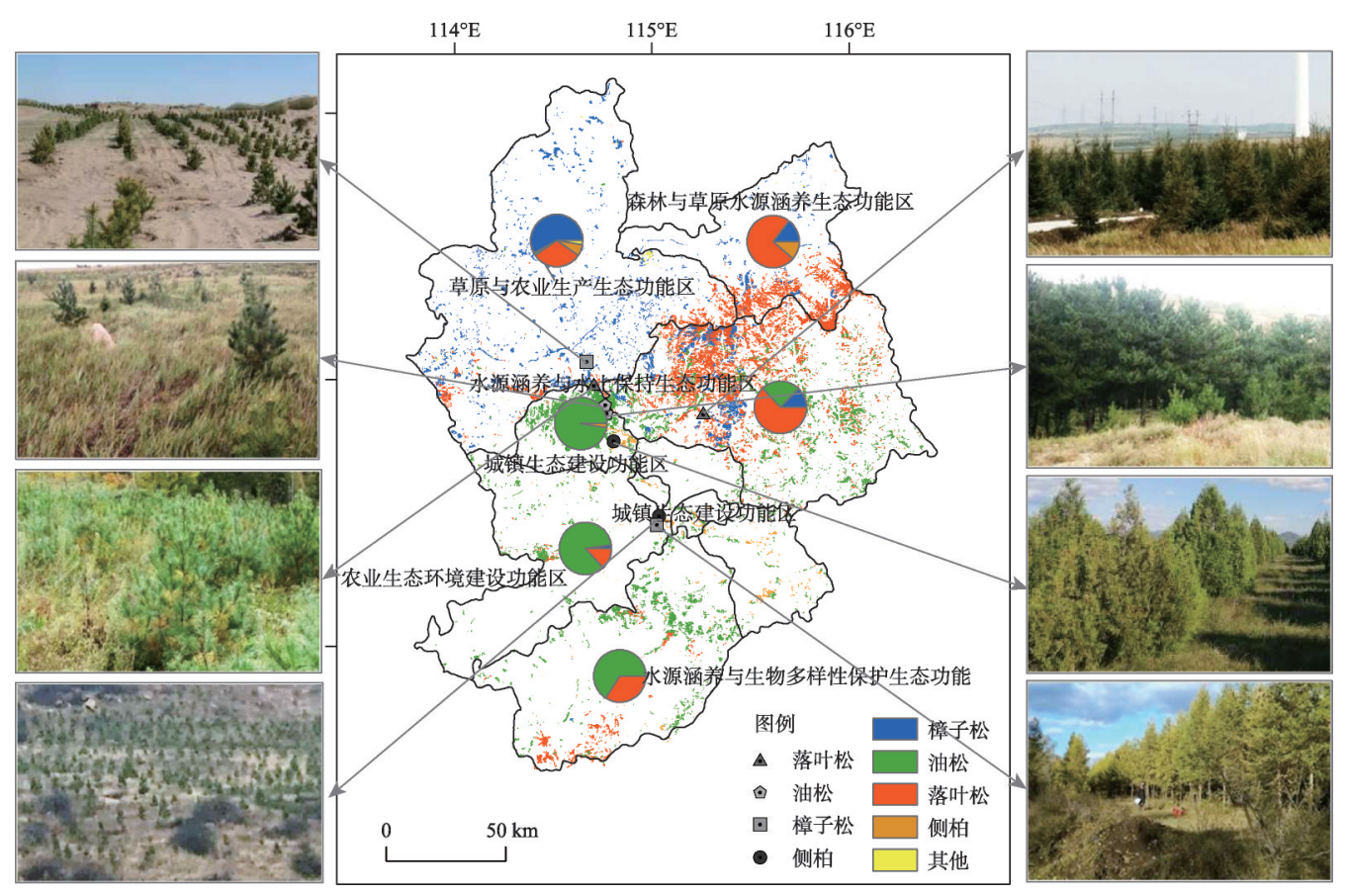

图 1 人工针叶林分区分布概况和样地位置

Fig. 1 Overview of the study area and location of sample sites

子模型。森林子模型由 5 个生物量库组成, 即叶、细根、粗根、细枝、粗枝和树干, 各 部分具有不同的 C、N、P养分含量，再根据土壤养分和气候还原植被生产力。CENTU$\mathrm{RY}$ 将凋落物分为结构库和代谢库，植物残体中的氮素与木质素比值决定了代谢库与结构 库的分布比率; 同时, 又将土壤有机质模型划分为活性库, 缓性库和惰性库, 结构库和 代谢库又决定了进人不同土壤有机质库中的养分和物质比例。水分子模型计算了不同土 壤层之间的水分循环和、各土壤分层中的水分含量、冰雪中水的含量以及每月的潜在蒸 散量 (PET), 即每月的蒸发 (Evaporation) 和潜在蒸腾（Transpiration）作用的水分损 失、各土壤层中的水分含量和雪中的水分含量。草原/农作物子模型可模拟不同的农作物 生长, 自然植物群落, 以及管理草原系统, 以月平均土壤温度和降水量为函数, 来计算 潜在的植物产量和养分需求。

本研究利用 CENTURY 模型的森林子模型、土壤有机质子模型和水分子模型分别模 拟 2016 年落叶松、油松、侧柏和樟子松两个林龄（幼龄林和中龄林）的生长季固碳、土 壤有机质 $(\mathrm{C} 、 \mathrm{~N} 、 \mathrm{P})$ 储量、土壤水分含量 (Asmos)、植被蒸发 (Evap)、林分 $\mathrm{N} 、 \mathrm{P}$ 养 分吸收和 $\mathrm{N}$ 淋溶损失等不同生态过程和功能产出, 模型主要输人参数如表 1 所示。

\subsection{2 模型参数化和模型验证}

（1）气候参数：模型设定自然状态下四种人工林的影响因素固定为气候和土壤，不 受人为干扰因素的影响。模型的气候参数来源于 SWAT 中国大气同化部分驱动数据集

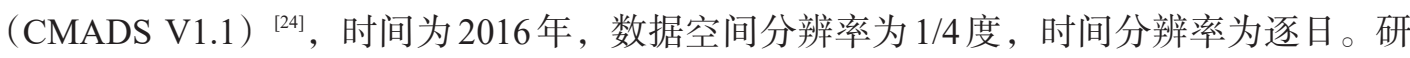
究提取数据集中的张家口格点数据, 在 ArcGIS 中采用克里格空间插值方法生成月均降 水、月均最高温、月均最低温的空间栅格图层, 然后根据四种针叶人工林的 8 个样地位 置信息提取不同样地的 CENTURY 模型气候输人参数, 提取后的气候输人参数和周边气 
表 1 CENTURY 模型输入参数

Table 1 Input parameters of CENTURY model

\begin{tabular}{clll}
\hline & \multicolumn{1}{c}{ 气候 } & \multicolumn{1}{c}{ 土壤 } & \multicolumn{1}{c}{ 植物 } \\
\hline 主要输人参数 & 月平均降水量 $/(\mathrm{cm} /$ 月 $)$ & 砂粒, 粉砂粒, 粘粒含量 $/ \%$ & 凋落物 $\mathrm{C} / \mathrm{N}, \mathrm{C} / \mathrm{P}$ \\
& 月平均最低温 $/{ }^{\circ} \mathrm{C}$ & 各层水分量 $/ \%$ & 淍落物量 $/\left(\mathrm{g} / \mathrm{m}^{2}\right)$ \\
月平均最高温 $/{ }^{\circ} \mathrm{C}$ & 容重 & $\mathrm{pH}$ & 叶 $\mathrm{C}, \mathrm{N}, \mathrm{P} /\left(\mathrm{g} / \mathrm{m}^{2}\right)$ \\
& & 土壤有机碳/ $\left(S O C, \mathrm{~g} / \mathrm{m}^{2}\right)$ & 枝 $\mathrm{C}, \mathrm{N}, \mathrm{P} /\left(\mathrm{g} / \mathrm{m}^{2}\right)$ \\
& 土壤碳库 $\mathrm{C} / \mathrm{N}, \mathrm{C} / \mathrm{P}$ & $\mathrm{N}, \mathrm{P} /\left(\mathrm{g} / \mathrm{m}^{2}\right)$ \\
& & 细根 $\mathrm{C}, \mathrm{N}, \mathrm{P} /\left(\mathrm{g} / \mathrm{m}^{2}\right)$ \\
& & 粗根 $\mathrm{C}, \mathrm{N}, \mathrm{P} /\left(\mathrm{g} / \mathrm{m}^{2}\right)$ \\
\hline
\end{tabular}

象站点相应参数对比, 浮动幅度在 $3 \% \sim 8 \%$ 范围内。

(2) 土壤参数: 土壤参数主要包括土壤厚度、土壤质地、 $\mathrm{pH}$ 值、土壤含水量、田间 持水量、调萎系数以及土壤有机碳含量等参数。除土壤有机碳和土壤厚度以外的土壤参 数（表2）来源于联合国粮农组织（FAO）和维也纳国际应用系统研究所（IIASA）所构

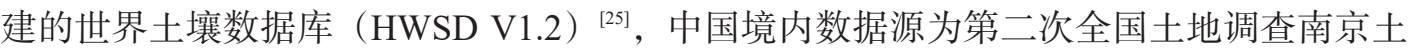
壤所提供的 $1: 100$ 万土壤数据。土壤数据和气候数据均由国家地球系统科学数据平台 (http://westdc.westgis.ac.cn/) 获取，土壤厚度参数从林业小班属性数据中提取。

\section{表 2 样地基本信息（CENTURY 模型本地化参数部分数据）}

Table 2 Essential information of samples

\begin{tabular}{|c|c|c|c|c|c|c|c|c|}
\hline & \multicolumn{2}{|c|}{ 落叶松 } & \multicolumn{2}{|c|}{ 油松 } & \multicolumn{2}{|c|}{ 樟子松 } & \multicolumn{2}{|c|}{ 侧柏 } \\
\hline & Young & Mature & Young & Mature & Young & Mature & Young & Mature \\
\hline 纬度 & 40.92 & 41.02 & 40.89 & 40.94 & 40.89 & 41.10 & 40.80 & 40.52 \\
\hline 经度 & 115.30 & 114.75 & 114.81 & 114.81 & 114.81 & 114.71 & 114.86 & 115.09 \\
\hline 砂粒 & 0.43 & 0.37 & 0.36 & 0.36 & 0.73 & 0.66 & 0.36 & 0.41 \\
\hline 粉砂 & 0.36 & 0.42 & 0.43 & 0.43 & 0.16 & 0.22 & 0.43 & 0.40 \\
\hline 粘土 & 0.21 & 0.21 & 0.21 & 0.21 & 0.11 & 0.12 & 0.21 & 0.19 \\
\hline 土壤容重 & 1.43 & 1.39 & 1.36 & 1.36 & 1.36 & 1.31 & 1.36 & 1.31 \\
\hline $\mathrm{pH}$ & 8 & 8 & 5.7 & 5.7 & 8 & 8.4 & 5.7 & 5.1 \\
\hline
\end{tabular}

（3）生态化学计量参数: 模型的土壤有机碳含量和植物生态化学计量参数（调落物 C、 $\mathrm{N} 、 \mathrm{P}$ 含量，植物器官 C、 N、P 木质素含量等）来源于文献资料 ${ }^{[26-56]}$ 。文献资料通过 对已经在国内正式出版的文献进行查询，分别搜集落叶松、油松、侧柏和樟子松文献中 幼龄林和中龄林的相应数据（表 1)。其中，研究设定幼龄林的林龄调研范围为 12 18 年, 中龄林的林龄调研范围为 26 36 年。一部分文献参数来源于张家口塞罕坝地区，研究获 取的参数大部分分布于与张家口临近的北京、内蒙古和山西部分华北区域 $\left(39^{\circ} \sim 42^{\circ} \mathrm{N}\right)$ 的相关文献 ${ }^{[26-49]}$; 少部分上述区域缺乏的数据则零散分布于 $35^{\circ} \sim 45^{\circ} \mathrm{N}$ 范围内 ${ }^{[00-56]}$ ，这一部 分的参数调研要求文献研究区必须与张家口具有相似的气候以及土壤条件，以保证模型 模拟的合理性。最终，结合文献数据 ${ }^{[26-56]}$, 根据 CENTURY 模型操作手册进行计算获取相 关参数值。部分参数数据则采用模型缺省值。

\subsection{3 模型验证}

主要从土壤有机碳密度、植被生物量和土壤体积含水量等三方面对 CENTURY 模型 
模拟结果和验证数据进行线性模拟，评价模拟结果的精确性。模型验证数据采用文献调 研数据，选择和样点林龄一致（或前后保持在 3 年以内）的林龄设置和具有相似立地条件 的文献调研区域，调研落叶松、油松、侧柏和樟子松幼龄林和中龄林的生物量、0 20 cm 层的 $S O C$ 含量、 $S O C$ 密度、土壤容重以及 $0 \sim 10 \mathrm{~cm}$ 层的土壤体积含水量。对仅有土壤有 机碳含量的文献数据, 结合土壤容重, 根据式（1）估算土壤碳密度。通过对几种指标的 拟合结果评价 CENTURY 模型模拟结果的适用性。

$$
\begin{gathered}
\text { 土壤碳密度 }=S O C \times B D \times 10 \\
S O C=\frac{\sum_{i=1}^{n} S O C_{i} \times B D_{i} \times d_{i}}{\sum_{i=1}^{n} B D_{i} \times d_{i}} \\
B D=\frac{\sum_{i=1}^{n} B D_{i} \times d_{i}}{D}
\end{gathered}
$$

式中: $S O C$ 为样地土壤有机碳含量 $(\mathrm{g} / \mathrm{kg}) ; S O C_{i}$ 为第 $i$ 个土层的有机碳含量 $(\mathrm{g} / \mathrm{kg}) ; B D$ 为样地土壤容重 $\left(\mathrm{g} / \mathrm{cm}^{3}\right) ; B D_{i}$ 为第 $i$ 个土层容重 $\left(\mathrm{g} / \mathrm{cm}^{3}\right) ; d_{i}$ 为第 $i$ 个土层厚度 $(\mathrm{cm}) ; D_{i}$ 为样地土层总厚度 $(\mathrm{cm})$ 。

\section{2 结果分析}

\section{1 模型适用性分析}

文献调研获取的验证数据和 CENTURY 模拟数据的线性拟合结果显示如图 2 所示: CENTURY 模型模拟的 SOC、生物量和土壤体积含水量结果和验证数据均有较好的相关 性。其中, 对 $S O C$ 的拟合效果最佳, 其次为生物量, 对土壤体积含水量的拟合效果较 差，决定系数 $\left(R^{2}\right)$ 分别为 $0.73 、 0.69$ 和 0.6 。从拟合系数来看, CENTURY 模型对生物 量和 $S O C$ 的模拟结果高于验证数据, 而对土壤体积含水量的模拟结果则比验证数据低近 $100 \%$ 。根据 CENTURY 模型对 SOC、生物量和土壤体积含水量的拟合效果，本文认为 CENTURY 模型可以拟合不同林龄人工针叶林的土壤养分含量、植被蒸发和植被养分固 持、吸收和损失等生态功能的变化和差异。
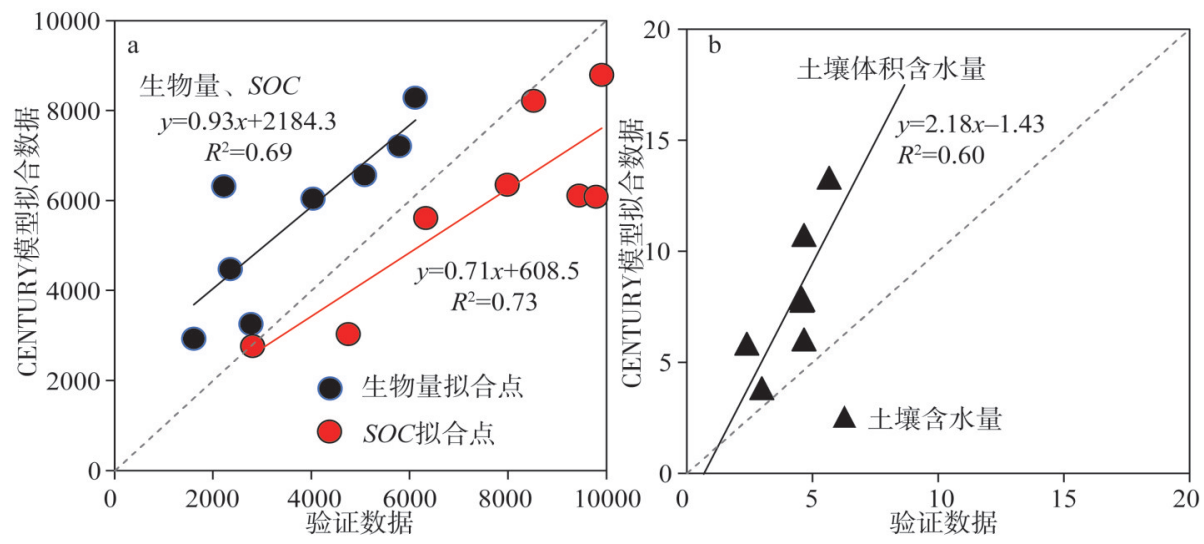

图 2 CENTURY 模型模拟结果验证

Fig. 2 Verification of CENTURY model simulation results 


\section{2 不同林龄人工针叶林种土壤养分固持能力比较}

随着林龄增加，落叶松、油松、侧柏和樟子松四种人工针叶林的土壤养分均呈现出 不同幅度的增加，增幅由大到小依次为油松 $(3.98 \%)>$ 落叶松 $(3.37 \%)>$ 侧柏 $(2.84 \%)>$ 樟子松 $(1.82 \%)$ 。油松的养分储量最高 $\left(8287.67 \mathrm{~g} / \mathrm{m}^{2}\right)$ ，其他依次是侧柏 $\left(6419.33 \mathrm{~g} / \mathrm{m}^{2}\right)$ 、落叶松 $\left(4894.63 \mathrm{~g} / \mathrm{m}^{2}\right)$ 和樟子松 $\left(2860.66 \mathrm{~g} / \mathrm{m}^{2}\right)$; 中龄林的土壤养分储量 由大到小依次是侧柏 $\left(10184.8 \mathrm{~g} / \mathrm{m}^{2}\right)>$ 樟子松 $\left(9973.69 \mathrm{~g} / \mathrm{m}^{2}\right)>$ 落叶松 $\left(9767.23 \mathrm{~g} / \mathrm{m}^{2}\right)>$ 油松 $\left(8859.43 \mathrm{~g} / \mathrm{m}^{2}\right)$ 。由图 $3 \mathrm{a}$ 可以看出, SOC决定了 $\mathrm{SOM}$ 总储量的高低顺序。有机 $\mathrm{N}$ 储 量增加幅度由大到小的排列顺序, 依次是侧柏>落叶松>樟子松>油松（图 $3 b$ ); 四种人工 针叶林土壤有机 $\mathrm{P}$ 的增幅排列顺序依次是: 落叶松>樟子松>侧柏>油松（图 $3 \mathrm{c}$ )。由此可 见，不同的林种对不同土壤养分元素的固持能力不同，樟子松和侧柏在土壤固碳能力优 于落叶松和油松, 油松在土壤固 $\mathrm{N}$ 方面的能力要优于其他林种, 而落叶松中龄林在土壤 固P方面的能力最佳。

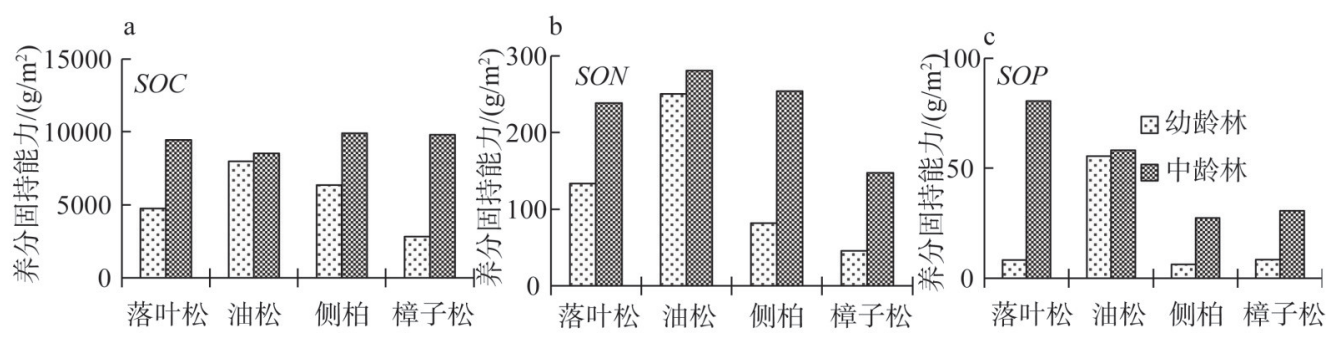

图 3 不同林龄林分土壤养分固持能力比较

Fig. 3 Comparison of soil nutrient retention capacity

\section{3 植被养分生产、消耗与养分损失评估}

\subsection{1 生长季植被固碳能力分析}

四种人工针叶林的 $\mathrm{C}$ 生产模拟结果显示：与幼龄林相比，樟子松、侧柏和油松中龄 林的年固碳量分别增加 $282.30 \mathrm{~g} / \mathrm{m}^{2} 、 279.71 \mathrm{~g} / \mathrm{m}^{2}$ 和 $27.58 \mathrm{~g} / \mathrm{m}^{2}$ ，而落叶松中龄林的年固 C 量则比幼龄林少，下降 $15.84 \mathrm{~g} / \mathrm{m}^{2}$; 中龄林中，樟子松>油松>落叶松>侧柏，幼龄林固碳 方面, 油松>落叶松>樟子松>侧柏; 侧柏在两个林龄的 C生产能力最差。除侧柏幼龄林 的固碳量在 7 月份到达峰值以外，其余不同林龄的林种（包括侧柏中龄林）均在 8 月底达 到峰值。侧柏幼龄林固碳量峰值期的提前可能受该样地降水峰值期提前的影响。

\subsection{2 生长季植被 $\mathrm{N} 、 \mathrm{P}$ 养分吸收分析}

$\mathrm{N} 、 \mathrm{P}$ 养分吸收总量表现为樟子松 $\left(21.87 \mathrm{~g} / \mathrm{m}^{2}\right)>$ 落叶松 $\left(10.23 \mathrm{~g} / \mathrm{m}^{2}\right)>$ 油松 $(9.14$ $\left.\mathrm{g} / \mathrm{m}^{2}\right)>$ 侧柏 $\left(8.76 \mathrm{~g} / \mathrm{m}^{2}\right)$ 。不同于其他林种出现多次 $\mathrm{N} 、 P$ 吸收峰值的现象（图4), 樟子 松属于高养分消耗的林种, 樟子松幼龄林的 $\mathrm{N} 、 \mathrm{P}$ 吸收在 7月份到达峰值后一直持续至生 长季结束。侧柏和落叶松的 N、P 吸收量在 6-7 月份达到最大, 幼龄林则在 9 月份出现另 一个 $N 、 P$ 吸收小高峰; 油松的 $N 、 P$ 吸收则 9月份达到峰值, 在 6-7 月份出现一个小高峰。

\subsection{3 植被 $\mathrm{N}$ 淋溶损失分析}

与幼龄林相比, 落叶松和油松中龄林的 $\mathrm{N}$ 淋溶损失量减少幅度分别为 $16.20 \mathrm{~g} / \mathrm{m}^{2}$ 和 $0.66 \mathrm{~g} / \mathrm{m}^{2}$ ，侧柏和樟子松的中龄林的 $\mathrm{N}$ 淋溶损失量则分别增加 $3.31 \mathrm{~g} / \mathrm{m}^{2}$ 和 $1.84 \mathrm{~g} / \mathrm{m}^{2}$ 。在 幼龄林组, 落叶松的 $\mathrm{N}$ 淋溶损失最大 $\left(20.21 \mathrm{~g} / \mathrm{m}^{2}\right)$, 此外依次为樟子松>油松>侧柏; 在 中龄林组, 油松的 $\mathrm{N}$ 淋溶损失最大 $\left(11.79 \mathrm{~g} / \mathrm{m}^{2}\right)$, 此外依次为樟子松>侧柏>油松。在整 

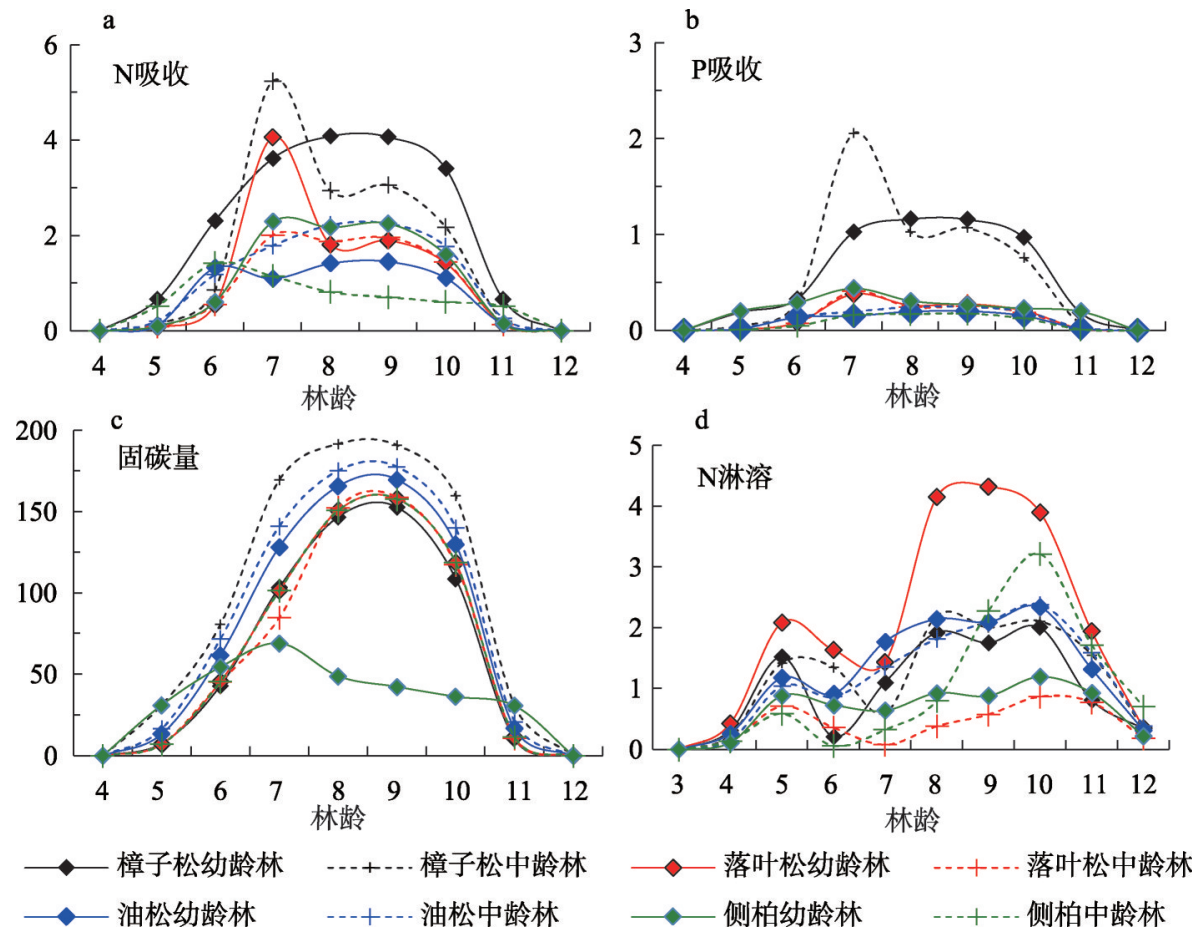

图4 不同林龄林种的 C生产以及 $\mathrm{N} 、 \mathrm{P}$ 养分消耗和损失对比

$\left(\mathrm{g} / \mathrm{m}^{2}\right)$

Fig. 4 Comparison of $\mathrm{C}$ production, and $\mathrm{N}$ and $\mathrm{P}$ nutrient consumption and loss

个生长季，不同林种的 $\mathrm{N}$ 淋溶损失时间序列曲线呈现多个波峰，时间分别集中于 5 月、 8 月和 10 月等 3 个月份。

\section{4 水分涵养功能比较}

CENTURY 模型水分模拟结果显示：随着林龄增加，四种人工针叶林蒸发量减少,土 壤含水量增加（图 5a), 这表明, 四种人工针叶林的水分涵养能力增加。其中, 不同林种 的平均蒸发量以落叶松最低, 为 $338.85 \mathrm{~mm}$, 其次依次为油松 $(399.86 \mathrm{~mm})<$ 侧柏 $(400.52 \mathrm{~mm})<$ 樟子松 $(401.81 \mathrm{~mm})$; 幼龄林蒸发量由大到小依次为: 樟子松 $>$ 侧柏 $>$ 油 松>落叶松, 中龄林不同林种的蒸发量是油松>樟子松 $>$ 侧柏 $>$ 落叶松。在土壤含水量方
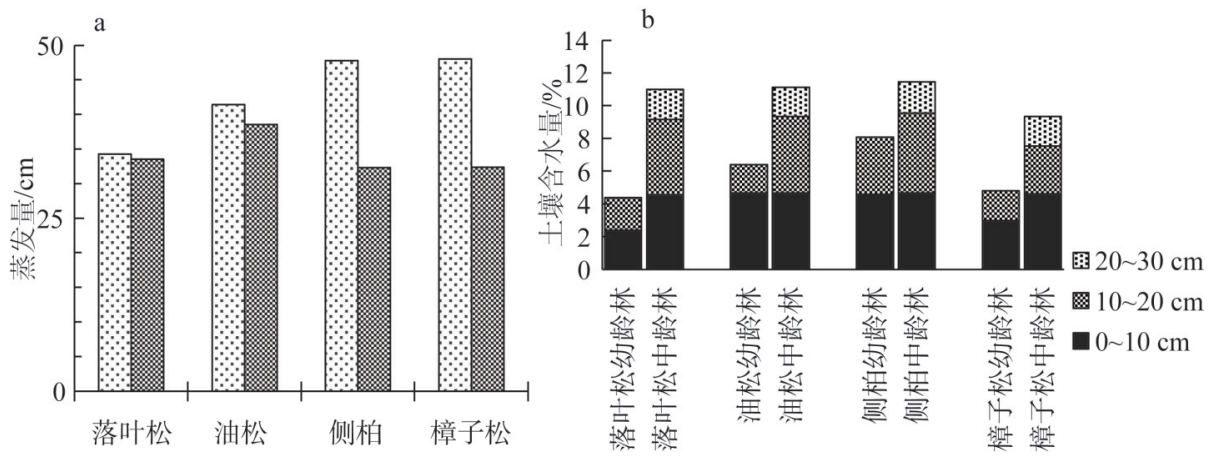

图 5 不同林龄林分蒸发与土壤含水量比较

Fig. 5 Comparison of evapotranspiration and soil moisture content 
面, 与幼龄林相比, 落叶松林土壤含水量增加了 1.5 倍, 增幅最大, 其余依次是樟子松 $(94.97 \%)>$ 油松 $(73.62 \%)>$ 侧柏 $(41.83 \%)$ 。

\section{3 结论与讨论}

\section{1 结论}

人工林体系能否最大限度的发挥其生态效益取决于它的林种结构和配置的合理性。 本研究针对主要针叶造林树种（落叶松、油松、侧柏和樟子松），通过 CENTURY 模型模 拟不同林种在改善土壤养分、土壤涵养水分功能，以及碳汇能力等方面的差异。在 C、 $\mathrm{N} 、 \mathrm{P}$ 养分涵养方面，随着林龄增加，落叶松人工林 $\mathrm{C} 、 \mathrm{~N} 、 \mathrm{P}$ 养分储量增加幅度最大，为 $7246.70 \mathrm{~g} / \mathrm{m}^{2}$, 其次为侧柏和樟子松人工林, 分别为 $4942.16 \mathrm{~g} / \mathrm{m}^{2}$ 和 $4814.52 \mathrm{~g} / \mathrm{m}^{2}$, 油松人 工林的养分储量的增加幅度最小。在 $\mathrm{N} 、 \mathrm{P}$ 养分消耗和损失方面，樟子松属于高养分吸收 的林种; 侧柏和樟子松的 $\mathrm{N}$ 淋溶损失呈增大趋势，落叶松和油松呈减小趋势。在水分涵 养方面, 与幼龄林相比, 落叶松人工林土壤含水量增加量最高, 为 $6.62 \%$, 且落叶松人 工林蒸发量始终低于区域蒸发量的年均值（380 450 mm)。油松、樟子松和侧柏人工林 土壤含水量的增加量分别为 $4.71 \% 、 4.55 \%$ 和 $3.77 \%$, 油松的蒸发量（385 414 mm）低于张 家口水源涵养和水保区的年均蒸发量 $(450 \mathrm{~mm})$, 高于其他区的年均蒸发量 $(380 \mathrm{~mm})$, 樟子松和侧柏蒸发量最高。综合各种功能分析, 落叶松可以作为水源涵养造林的优选树 种，油松可以作为水源涵养区的第二优选树种。不同于陈文静等 ${ }^{[11]}$ 认为常绿针叶林导致 土壤涵水功能的退化, 本研究中落叶松和油松对土壤的持水功能改造最佳, 这不仅和调 落物的易分解性有关，也可能和土壤厚度与造林前的环境特征差异有关。

\section{2 讨论}

根据结果，张家口目前人工针叶林空间配置格局（图 1）基本合理，建议适当增加 落叶松在张家口水源涵养功能区域的占比，主要包括坝下水源涵养和水土保持生态功能 区和水源涵养与生物多样性生态包括功能区，坝上森林与草原水源涵养生态功能区则建 议增加油松占比, 减少侧柏占比; 考虑到樟子松和落叶松对土壤养分的消耗能力, 建议 可以在农业面源污染区的下游区域试验推广落叶松和樟子松。同时，增加坝下水源涵养 和水土保持、水源涵养与生物多样性/农业生态环境建设、城镇生态建设功能区的林种多 样性水平。

运用CENTURY 模型具有很多不确定性，模型参数的本地化是保证模型运行准确性 的重要因素。本文参阅大量具有相似立地条件和造林树种文献, 并对部分缺乏的数据进 行合理的推算, 得到合理范围内的计算值。仍然有一部分数据采用模型缺省值, 这可能 是导致模型拟合结果有待提高的主要原因。

\section{参考文献(References):}

[1] 于法展, 张忠启, 陈龙乾, 等. 江西庐山自然保护区不同林地水源涵养功能研究. 水土保持研究, 2014, 21(5): 255259. [YU F Z, ZHANG Z Q, CHEN L Q, et al. Study on water conservation function of different forestlands in Lushan Nature Reserve, Jiangxi province. Research of Soil and Water Conservation, 2014, 21(5): 255-259.]

[2] 蔡婷, 李阿瑾, 宋坤, 等. 黄浦江上游近自然混交林和人工纯林水源涵养功能评价. 水土保持研究, 2015, 22(2): 3640. [CAI T, LI A J, SONG K, et al. Study on water conservation of near-natural forest and pure forest in upper reaches of the Huangpu River. Research of Soil and Water Conservation, 2015, 22(2): 36-40.]

[3] SILVEIRA M L, COMERFORD N B, REDDY K R, et al. Soil properties as indicators of disturbance in forest ecosystems of Georgia, USA. Ecological Indicators, 2009, 9(4): 740-747. 
[4] RODRIGUEZ-LOINAZ G, ONAINDIA M, AMEZAGA I, et al. Relationship between vegetation diversity and soil functional diversity in native mixed-oak forests. Soil Biology and Biochemistry, 2008, 40(1): 49-60.

[5] 鲁晨曦, 张军泽, 赵廷阳, 等. 我国人工林生态系统的水成本核算. 自然资源学报, 2016, 31(5): 743-754. [LU C X, ZHANG J Z, ZHAO T Y, et al. Water costs of afforestation and natural-restoration in China. Journal of Natural Resources, 2016, 31(5): 743-754.]

[6] 何斌, 黄承标, 秦武明, 等. 不同植被恢复类型对土壤性质和水源涵养功能的影响. 水土保持学报, 2009, 23(2): 7174, 94. [HE B, HUANG C B, QIN W M, et al. Effect of different vegetation restoration types on soil properties and water conservation function. Journal of Soil and Water Conservation, 2009, 23(2): 71-74, 94.]

[7] 康冰, 刘世荣, 蔡道雄, 等. 南亚热带不同植被恢复模式下土壤理化性质. 应用生态学报, 2010, 21(10): 2479-2486. [KANG B, LIU S R, CAI D X, et al. Soil physical and chemical characteristics under different vegetation restoration patterns in China south subtropical area. Chinese Journal of Applied Ecology, 2010, 21(10): 2479-2486.]

[8] 李文博, 吕振刚, 黄选瑞, 等. 塞罕坝华北落叶松人工林生产力及其空间分布预测. 自然资源学报, 2019, 34(7): 13651375. [LI W B, LYU Z G, HUANG X R, et al. Predicting productivity and spatial distribution of Larix principis-rupprechtii Plantation. Journal of Natural Resources, 2019, 34(7): 1365-1375.]

[9] 莫菲, 李叙勇, 贺淑霞, 等. 东灵山林区不同森林植被水源涵养功能评价. 生态学报, 2011, 31(17): 5009-5016. [MO F, LI X Y, HE S X, et al. Evaluation of soil and water conservation capacity of different forest types in Dongling Mountain. Acta Ecologica Sinica, 2011, 31(17): 5009-5016.]

[10] 秦嘉海, 金自学, 王进, 等. 祁连山不同林地类型对土壤理化性质和水源涵养功能的影响. 水土保持学报, 2007, 21 (1): 92-94. [QIN J H, JIN Z X, WANG J, et al. Influence of different type of forest land on soil physico-chemical property and function of water conservation. Journal of Soil and Water Conservation, 2007, 21(1): 92-94.]

[11] 陈文静, 祁凯斌, 黄俊胜, 等. 川西不同树种人工林对土壤涵水能力的影响. 生态学报, 2017, 37(15): 4998-5006. [CHEN W J, QI K B, HUANG J S, YANG T H, et al. Effect of reforestation with different tree species on soil waterholding capacity in Western Sichuan province. Acta Ecologica Sinica, 2017, 37(15): 4998-5006.]

[12] PARTON W J, STEWART J W B, COLE C V. Dynamics of C, N, P and S in grassland soils: A model. Biogeochemistry, 1988, 5(1): 109-131.

[13] 陈泮勤. 地球系统碳循环. 北京: 科学出版社, 2004: 357-381. [CHEN P Q. Earth System Carbon Cycle. Beijing: Science Press, 2004: 357-381.]

[14] PARTON W J, RASMUSSEN P E. Long-term effects of crop management in wheat-fallow: II. CENTURY Model Simulations. Soil Science Society of America Journal, 1994, 58(2): 530-536.

[15] DIMASSI B, GUENET B, SABY N P A, et al. The impacts of CENTURY model initialization scenarios on soil organic carbon dynamics simulation in French long-term experiments. Geoderma, 2018, 311(1): 25-36.

[16] GISJMAN, AOBERSON, H TIESSELL, et al. Limited applicability of the CENTURY model to highly weathered tropical soils. Agronomy Journal, 1996, 88(6): 894-903.

[17] ALTHOFF T, MENEZES R S C, PINTO A D S, et al. Adaptation of the century model to simulate C and N dynamics of Caatinga dry forest before and after deforestation. Agriculture, Ecosystems \& Environment, 2018, 254: 26-34.

[18] 黄忠良. 运用 Century 模型模拟管理对鼎湖山森林生产力的影响. 植物生态学报, 2000, 24(2): 175-179. [HUANG Z L. Application of CENTURY model to management effects in the productivity of forests in Ding Hushan. Acta Phytoecologica Sinica, 2000, 24(2): 175-179.]

[19] 高崇升, 杨国亭, 王建国, 等. CENTURY 模型在农田生态系统中的应用及其参数确定. 土壤与作物, 2006, 22(1): 5052. [GAO C S, YANG G T, WANG J G, et al. CENTURY Model's application in farmland ecosystem and its parameters' determination. Soil and Crop, 2006, 22(1): 50-52.]

[20] 陈辰, 王靖, 潘学标. CENTURY 模型在内蒙古草地生态系统的适用性评价. 草地学报, 2012, 20(6): 1011-1019. [CHEN C, WANG J, PAN X B. Validation and adaptability evaluation of grass ecosystem Model CENTURY in Inner Mongolia. Acta Agrestia Sinica, 2012, 20(6): 1011-1019.]

[21] 高鲁鹏, 梁文举, 姜勇, 等. 利用 CENTURY 模型研究东北黑土有机碳的动态变化. 应用生态学报, 2004, 15(5): 36401. [GAO L P, LIANG W J, JIANG Y, et al. Dynamics of organic C in black soil of Northeast China, simulated by CENTURY model I. Accumulation of soil organic carbon under natural conditions. Chinese Journal of Applied Ecology, 2004, 15(5): 36- 401.]

[22] 方东明. 基于 CENTURY 模型模拟火烧对大兴安岭兴安落叶松林碳动态的影响. 应用生态学报, 2012, 23(9): 2411- 
2421. [FANG D M. Impact of fire on carbon dynamics of larix gmelinii forest in Daxing'an Mountains of Northeast China: A simulation with CENTURY model. Chinese Journal of Applied Ecology, 2012, 23(9): 2411-2421.]

[23] 邵思雅, 李方方, 张晶. 大兴安岭森林生态系统氮磷元素对碳循环的影响. 北京师范大学学报: 自然科学版, 2015, 51(3): 306-312. [SHAO S Y, LI F F, ZHANG J. Impact of nitrogen and phosphorus limitation on carbon cycle of forest ecosystem in the Greater Khingan Mountains. Journal of Beijing Normal University: Natural Science, 2015, 51(3): 306312.]

[24] 孟现勇. SWAT 模型中国大气同化驱动数据集(CMADS V1.1). 寒区旱区科学数据中心, 2016, Doi: 10.3972/westdc.002.2016.db. [MENG X Y. China meteorological assimilation driving datasets for the SWAT. Scientific Data Center for Cold and Arid Regions, 2016, Doi: 10.3972/westdc.002.2016.db.]

[25] WIEDER W R, BOEHNERT J, BONAN G B, et al. Regridded Harmonized World Soil Database v1.2. Oak Ridge National Laboratory Distributed Active Archive Center, Oak Ridge, Tennessee, USA, 2014, https://doi.org/10.3334/ORNLDAAC/1247.

[26] 曹吉金鍂. 北京北部山区不同林龄的油松和侧柏人工林碳库研究. 北京: 北京林业大学, 2011. [CAO J X. Above- and belowground carbon pools in different ages of Chinese pine and oriental arborvitae plantation forests in Northern Mountain Areas of Beijing. Beijing: Beijing Forestry University, 2011.]

[27] 陈立新, 陈祥伟. 落叶松人工林调落物与土壤肥力变化的研究. 应用生态学报, 1998, 9(6): 581-586. [CHEN L X, CHEN X W. Larch litter and soil fertility. Chinese Journal of Applied Ecology, 1998, 9(6): 581-586.]

[28] 韩有志, 宋日飞. 华北落叶松人工林根系生物量的研究. 林业科技通讯, 1997, (7): 17-19. [HAN Y Z, SONG R F. Study on root biomass of Larch. Forest Science and Technology, 1997, (7): 17-19.]

[29] 黄晓强, 信忠保, 赵云杰, 等. 北京山区典型人工林土壤团聚体组成及其有机碳分布特征. 水土保持学报, 2016, 30 (1): 236-243. [HUANG X Q, XIN Z B, ZHAO Y J, et al. Soil aggregate composition and distribution characteristics of soil organic carbon of typical plantations in mountainous area of Beijing. Journal of Soil and Water Conservation, 2016, 30(1): 236-243.]

[30] 纪文婧, 程小琴, 韩海荣, 等. 不同林龄华北落叶松人工林生物量及营养元素分布特征. 应用与环境生物学报, 2016, (2): 277-284. [JI W J, CHENG X Q, HAN H R, et al. The biomass and nutrient distribution in larix principis-ruppechtii magyr plantations at different forest age. Chinese Journal of Applied and Environmental Biology, 2016, (2): 277-284.]

[31] 李靖. 不同林龄杉木和华北落叶松人工林氮磷养分特征与根构型研究. 杨凌: 西北农林科技大学, 2012. [LI J. A study on nutrients and root architecture of different aged-Cuunninghamia Lanceolata and Larix Principis-Rupperchtii Mayr plantations. Yangling: Northwest Agriculture \& Forestry University, 2012.]

[32] 李倩茹. 冀北山地天然次生林与人工林典型生态系统服务功能研究: 以天然次生杨桦林与人工落叶松林为例. 保 定: 河北农业大学, 2011 .[LI Q R. Typical ecosystem services of secondary forest and plantation in North Moutain of Hebei: A case study of secondary poplar-birch forest and larch plantation. Baoding: Agricultural University of Hebei, 2011.]

[33] 梁芳. 间伐对北京山区侧柏人工林碳动态影响的研究. 北京: 北京林业大学, 2013. [LIANG F. The effects of thinning treatment on carbon dynamic of Chinese arborvitae plantation in mountain area of Beijing. Beijing: Forest University of Beijing, 2013.]

[34] 刘红梅, 吕世杰, 刘清泉, 等. 多伦县樟子松人工林生物量及碳储量研究. 内蒙古农业大学学报: 自然科学版, 2013, (3): 49-53. [LIU H M, LYU S J, LIU Q Q, et al. Biomass and carbon storage of the Pious sylvestris var. Mongolica Litv. Plantation in the Duolun county. Journal of Inner Mongolia Agricultural University, 2013, (3): 49-53.]

[35] 逯军峰, 王辉, 曹靖, 等. 不同林龄油松人工林枯枝落叶层持水性及养分含量. 浙江农林大学学报, 2007, 24(3): 319325. [LU J F, WANG H, CAO J, et al. Water holding capacity and nutrients of litter layers in a Pinus tabulaeformis Plantation at different ages in Mount Xiaolong of Gansu. Journal of Zhejiang Forestry College, 2007, 24(3): 319-325.]

[36] 马长明, 赵辉, 牟洪香, 等. 燕山山地华北落叶松人工林碳密度及分配特征. 水土保持学报, 2017, 31(5): 208-214. [MA C M, ZHAO H, MU H X, et al. Carbon density and its allocation characteristics of Larix principis-rupprechtii Plantation in Yanshan Mountainous Area. Journal of Soil and Water Conservation, 2017, 31(5): 208-214.]

[37] 牛沙沙, 周永斌, 刘丽颖, 等. 不同林龄樟子松人工林土壤理化性质. 东北林业大学学报, 2015, (2): 47-52, 60. [NIU S S, ZHOU Y B, LIU L Y, et al. Soil properties in Pinus sylvestris var. mongolica Plantation of different ages. Journal of Northeast Forestry University, 2015, (2): 47-52, 60.]

[38] 邱新彩,彭道黎, 李伟丽, 等. 北京延庆区不同林龄油松人工林土壤理化性质. 应用与环境生物学报, 2018, 24(2): 221-231. [QIU X C, PENG D L, LI W L, et al. Soil physicochemical properties of Pinus Tabuliformis Plantations of dif- 
ferent ages in Yanqing, Beijing. Chinese Journal of Applied and Environmental Biology, 2018, 24(2): 221-231.]

[39] 沈国舫, 董世仁, 聂道平. 油松人工林养分循环的研究I. 营养元素的含量及分布. 北京林业大学学报, 1985, 4: 1-14. [SHEN G F, DONG S R, NIE D P. Studies on the nutrient cycling of Pinus Tabuliformis Plantation I. Content and distribution of nutrient elements. Journal of Beijing Forestry University, 1985, 4: 1-14.]

[40] 淑敏, 王东丽, 王凯, 等. 不同林龄樟子松人工林针叶一调落叶一土壤生态化学计量特征. 水土保持学报, 2018, 156 (3): 177-182. [SHU M, WANG D L, WANG K, et al. Ecological stoichiometry characteristics of needle leaves-littersoils in Pinus sylvestris var. mongolica Plantation with different ages. Journal of Soil and Water Conservation, 2018,156 (3): 177-182.]

[41] 宋涛, 王铁柱, 高杰. 侧柏人工林生态系统营养元素含量分布的研究. 北京林业大学学报, 1997, 19(s2): 61-66. [SONG T, WANG T Z, GAO J. A study on distribution of nutrient element contents in a Paltycladus orenatils Plantation ecosystem. Journal of Beijing Forestry University, 1997, 19(s2): 61-66.]

[42] 王瑞利. 基于多模型的森林一草原交错带碳动态模拟研究. 呼和浩特: 内蒙古农业大学, 2017. [WANG R L. Simulation of carbon dynamics in forest-steppe ecotone based on multiple models. Hohhot: Inner Mongolia Agricultural University, 2017.]

[43] 王文新, 郭景唐, 陈峻崎. 华北落叶松各器官营养元素分布及季节变化. 北京林业大学学报, 1992, 14(s1): 124-129. [WANG W X, GUO J T, CHEN J Q. Distributions and seasonla changes of nutrient elements contents in different organ of Larix principis-rupprechtii. Journal of Beijing Forestry University, 1992, 14(s1): 124-129.]

[44] 徐娟. 北京山区典型森林枯落物层生态功能研究. 北京: 北京林业大学, 2010. [XU J. Ecological functions of forest floor in forest ecosystems in Beijing Mountain Area. Beijing: Beijing Forestry University, 2010.]

[45] 姚延寿. 京西山区油松侧柏人工混交林生物量及营养元素循环的研究. 北京林业大学学报, 1989, 11(2): 38-46. [YAO Y S. Studies on the biomass and nutrient cycling of the mixed plantation of Pinus tabulaeformis and Platycladus orientlis in Xishan region, Beijing. Journal of Beijing Forestry University, 1989, 11(2): 38-46.]

[46] 袁吉有, 欧阳志云, 郑华, 等. 科尔沈沙地不同恢复方式下生态系统营养元素积累与分配特征. 云南大学学报: 自然 科学版, 2018, 40(4): 795-803. [YUAN J Y, OUYANG Z H, ZHENG H, et al. Nutrient elements' accumulation and distribution pattern of different grassland restoration approaches in Horqin Sandy Land. Journal of Yunnan University, 2018, 40(4): 795-803.]

[47] 袁立敏, 间德仁, 王熠青, 等. 沙地樟子松人工林碳储量研究. 内蒙古林业科技, 2011, 37(1): 9-13. [YUAN L M, YAN D R, WANG Y Q, et al. Carbon storage of Pinus sylvestris var. mongolica Litv. plantation in sandy land. Journal of Inner Mongolia Forestry Science \&Technology, 2011, 37(1): 9-13.]

[48] 张利敏, 王传宽, 唐艳. 11 种温带树种粗木质残体分解初期结构性成分和呼吸速率的变化. 生态学报, 2011, 31(17): 5017-5024. [ZHANG L M, WANG C K, TANG Y. Changes in structural components and respiration rates of coarse woody debris at the initial decomposition stage for 11 temperate tree species. Acta Ecologica Sinica, 2011, 31(17): 50175024.]

[49] 张田田. 华北落叶松人工林生物量与碳储量的研究. 北京: 北京林业大学, 2012. [ZHANG T T. Biomass and carbon storage of Larix principis-rupprechtii. Forest Plantation. Beijing: Beijing Forestry University, 2012.]

[50] 万淑清, 沈海龙, 丛健. 樟子松林木养分元素含量与分布. 东北林业大学学报, 2016, 37(1): 15-17. [DIAO S Q, SHEN H L, CONG J. Content and distribution of nutrient elements in trees of Pinus sylvestris var. mongolica. Journal of Northeast Forestry University, 2016, 37(1): 15-17.]

[51] 贾炜玮, 李凤日, 董利虎, 等. 基于相容性生物量模型的樟子松林碳密度与碳储量研究. 北京林业大学学报, 2012, 34 (1): 6-13. [JIA W W, LI F R, DONG L H, et al. Carbon density and storage for Pinus sylvestris var. mongolica Plantation based on compatible biomass model. Journal of Beijing Forestry University, 2012, 34(1): 6-13.]

[52] 程小琴. 山西太岳山油松人工林土壤碳特征对林分密度调控响应的研究. 北京: 北京林业大学, 2014. [CHEN X Q. Responses of soil carbon character to tree density in Pinus tabulaeformis plantations in Mt. Taiyue, Shanxi, China. Beijing: Beijing Forestry University, 2014.]

[53] 宋娅丽, 韩海荣, 康峰峰. 山西太岳山不同林龄油松林生物量及碳储量研究. 水土保持研究, 2016, 23(1): 29-33. [SONG Y L, HAN H R, KANG F F. Study on biomass and carbon storage with age-chronosequence in Pinus tabulaeformis Forest in Taiyue Mountain of Shanxi province. Research of Soil and Water Conservation, 2016, 23(1): 29-33.]

[54] 王晓佳. 晋西主要林分因子对土壤有机碳及养分含量影响研究. 北京: 北京林业大学, 2016. [WANG X J. Study on soil organic carbon and nutrient content of the main forest factors in Western Shanxi. Beijing: Beijing Forestry University, 2016.] 
[55] 夏菁,魏天兴, 陈佳澜, 等. 黄土丘陵区人工林养分循环特征. 水土保持学报, 2010, 24(3): 89-93. [XIA J, WEI T X, CHEN J L, et al. Biological cycling of nutrients of plantation in hilly Loess Plateau. Journal of Soil and Water Conservation, 2010, 24(3): 89-93.]

[56] 张秀娟, 吴楚, 梅莉, 等. 水曲柳和落叶松人工林根系分解与养分释放. 应用生态学报, 2006, 17(8): 1370-1376. [ZHANG X J, WU C, MEI L, et al. Root decomposition and nutrient release of Fraxinus manshurica and Larix gmelinii Plantations. Chinese Journal of Applied Ecology, 2006, 17(8): 1370-1376.]

\title{
Difference assessment on ecological functions of artificial coniferous forests in water conservation area of Northwestern Hebei
}

\author{
SUN Fei-fei, ZHANG Zeng-xiang, ZUO Li-jun, ZHAO Xiao-li, \\ PAN Tian-shi, ZHU Zi-juan, WANG Xiao, LIU Fang, YI Ling, \\ WEN Qing-ke, XU Jin-yong, HU Shun-guang \\ (Institute of Remote Sensing and Digital Earth, CAS, Beijing 100101, China)
}

\begin{abstract}
Artificial afforestation is considered to be one of the most effective ecological methods to increase carbon sequestration, conserve water and soil, and improve water quality. This study focuses on the main coniferous afforestation tree species (Dahurian larch, Pinus tabulaeformis, Oriental arborvitae and Pinus sylvestris var. mongolical) of Zhangjiakou, based on long- term soil and meteorological data, as well as physiological parameters data of afforestation tree species obtained from literature data with similar conditions, and localized the CENTURY model. The validation data derived from literature investigation is used to evaluate the fitting precision of CENTURY model. The results showed that the CENTURY model had a good simulation on SOC, biomass and soil water content, which could be used for the ecological function assessment of artificial coniferous forest in Zhangjiakou. Compared with young plantation, the results of CENTURY model simulation show that the total reserves of soil C, N and P in half- mature forest of Dahurian larches, Pinus tabulaeformis, Oriental arborvitae and Pinus sylvestris var. mongolical increased by $3.37 \%, 3.98 \%, 2.84 \%$ and 1.82\%, respectively, and the soil water contents increased by $151.25 \%, 73.62 \%, 41.83 \%$ and $94.98 \%$, respectively. The average evapotranspiration of two ages of Dahurian larches $(338.85 \mathrm{~mm})<$ Pinus tabulaeformis $(399.86 \mathrm{~mm})<$ Oriental arborvitae $(400.52 \mathrm{~mm})<$ Pinus sylvestris var. mongolical $(401.82 \mathrm{~mm})$ were compared between different forest species. Dahurian larches can be used as the best afforestation tree species in water conservation area. Pinus sylvestris var. mongolical and Dahurian larches were suggested to be promoted in the downstream areas polluted by agricultural production. This study can provide a reference for ecological engineering construction aimed at different ecological function goals.
\end{abstract}

Keywords: ecological function; CENTURY model; water conservation function; artificial coniferous forest; nutrient fixation 